\title{
Local anesthesia and anxiolytic techniques for oculoplastic surgery
}

This article was published in the following Dove Medical Press journal: Clinical Ophthalmology

\author{
Edsel B Ing' \\ Justine Philteos ${ }^{2}$ \\ Galina Sholohov ${ }^{3}$ \\ David Ta Kim' \\ Navdeep Nijhawan' \\ Patrick W Mark ${ }^{4}$ \\ Jaclyn Gilbert ${ }^{4}$ \\ 'Department of Ophthalmology and \\ Vision Sciences, University of Toronto, \\ Toronto, ON, Canada; ${ }^{2}$ School of \\ Medicine, University of Toronto, \\ Toronto, ON, Canada; ${ }^{3}$ Barzilai \\ Medical Center, Ashkelon, Israel; \\ ${ }^{4}$ Department of Anesthesia, Michael \\ Garron Hospital, University of \\ Toronto, Toronto, ON Canada
}

Correspondence: Edsel B Ing

Department of Ophthalmology and

Vision Sciences, Michael Garron Hospital, 650 Sammon Avenue, K306, Toronto,

ON M4C 5M5, Canada

Fax + I 4163853880

Email edinglidstrab@gmail.com

\begin{abstract}
This study discusses local anesthetic agents, administration techniques, ancillary considerations, and safety precautions for oculoplastic surgery including eyelid, lacrimal, orbital, and temporal artery biopsy procedures. Methods for reducing patient apprehension and discomfort including systemic premedication, topical pre-anesthetic, visual, auditory and tactile distraction techniques, regional blocks, small gauge needles, warmed lidocaine, and buffered lidocaine are discussed.
\end{abstract}

Keywords: local anesthesia, anxiolytics, oculoplastics, eyelid, orbit, lacrimal, temporal artery biopsy

\section{Introduction}

Local anesthesia induces a reversible loss of sensation and loss of muscle contraction, in a limited region of the body without altering the level of consciousness. Local anesthetics are membrane-stabilizing agents that inhibit voltage-gated sodium channels in the neuronal cell membrane, increasing action potential thresholds, thereby decreasing the perception of pain and inhibiting muscular contraction. ${ }^{8}$ The majority of oculoplastic procedures including eyelid surgery and temporal artery biopsy are routinely performed in adults with local anesthetic to avoid the increased time and expense of general anesthesia and the potential side effects of cardiorespiratory compromise, post-operative nausea and vomiting, and rarely malignant hyperthermia. ${ }^{66}$ The optimal administration of local anesthetic is critical to the success of awake procedures as it ensures patient cooperation, aids hemostasis, facilitates intraoperative adjustments if needed, and enhances the patient's surgical experience and perception of good care.

\section{Pre-operative considerations}

Most eyelid procedures can be performed in a minor surgery setting under local anesthesia, but pre-operative medical clearance may still be required. The eyelids are quite vascular, and as such a thorough medication history should be obtained with special attention to anticoagulants, especially the newer anticoagulants such as dabigatran, apixaban, and rivaroxaban. ${ }^{31}$ Pre-operative dialog including explanations of the procedure, cosmetic concerns, ${ }^{32}$ and the provision of treatment options such as the type, dose, and timing of sedation may help decrease patient's anxiety during awake procedures. ${ }^{63}$

\section{Local anesthetic agents}

The incongruity of injectable local anesthetics is that although they provide anesthesia, the injection itself initially causes pain due to the needle puncture, the pressure of the 
solution entering the injection site, and the acidic $\mathrm{pH}$ of the anesthetic solution. We review the local anesthetic agents and different techniques to decrease patient's pain and anxiety during the local anesthetic injection and periocular injections.

The mechanism of action of local anesthetics is the interruption of axon depolarization, by preventing the influx of sodium through the nerve cell membranes. Local anesthetics can be either ester or amide based. Ester local anesthetics used in ophthalmology are predominantly topical preparations including tetracaine, proparacaine, and cocaine. Topical anesthetic eye drops are instilled at the start of most oculoplastic procedures to minimize the stinging from antiseptics and to facilitate fitting of cornea protectors. Upon initial instillation, tetracaine $0.5 \%$ eye drops are more uncomfortable than proparacaine $0.5 \%$ eye drops. ${ }^{6}$

Most of the injectable local anesthetics are amide local anesthetics, eg, lidocaine, prilocaine, mepivacaine, bupivacaine, levobupivacaine, and ropivacaine.

Lidocaine hydrochloride $1 \%-2 \%$ without and with epinephrine $(1: 100,000$ or $1: 200,000)$ is the most commonly used injectable agent for local anesthesia. The onset of action is within 1 minute and can last 1-3 hours depending on the strength of the preparation, and the duration of action is longer if epinephrine is added to the solution. The maximum safe dose of tumescent lidocaine is $5 \mathrm{mg} / \mathrm{kg}$ and with epinephrine $7 \mathrm{mg} / \mathrm{kg}$. One milliliter of $1 \%$ lidocaine contains $10 \mathrm{mg}$ of lidocaine.

Bupivacaine hydrochloride $0.50 \%-0.75 \%$ is a longeracting agent than lidocaine with a duration of 6-8 hours. In comparison to lidocaine, bupivacaine has a slower onset of action at 10 minutes, but can be used in combination with the former. The maximum safe dose of bupivacaine without epinephrine is $2.5 \mathrm{mg} / \mathrm{kg}$ and with epinephrine is $3.5 \mathrm{mg} / \mathrm{kg} .{ }^{56}$

Ropivacaine hydrochloride $0.75 \%-1 \%$ (Naropin $^{\circledR}$, AstraZeneca, Missisauga, ON, Canada) has less potential for cardiotoxicity and central nervous system (CNS) toxicity than bupivacaine. ${ }^{59}$ Ropivacaine has similar duration of action to bupivacaine.

An epinephrine concentration of $10 \mu \mathrm{g} / \mathrm{mL}(1: 100,000)$ in the local anesthetic is thought to provide adequate vasoconstriction for eyelid surgery, with adequate hemostatic effect within 1 minute. ${ }^{61}$

\section{Systemic anxiolytics and analgesics}

Systemic anxiolytics and analgesics can be administered prior to local anesthetic injection. Lorazepam (Ativan ${ }^{\circledR}$, Pfizer Canada, North York, ON, Canada) is a commonly used benzodiazepine with anxiolytic, sedative, and hypnotic properties. Its administration is sublingual or oral, and the usual adult dose is $1-2 \mathrm{mg}$. Given orally, lorazepam reaches its peak concentration in approximately 2 hours. Side effects of lorazepam include dizziness, weakness, unsteadiness, hypotension, cognitive impairment, behavioral disinhibition, and respiratory depression. ${ }^{3}$ In some cases, there can be paradoxical effects with benzodiazepines, such as increased hostility, aggression, angry outbursts, and psychomotor agitation. ${ }^{43}$ Surgeons should be cognizant that sedatives may affect intraoperative upper eyelid margin position.

Propofol and benzodiazepines such as midazolam (Versed $^{\circledR}$, Hoffman-La Roche Limited, Missisauga, ON, Canada) are commonly used intravenous sedatives that can be administered prior to local anesthetic injection. Midazolam and propofol do not have analgesic properties but provide comfort to the patient via their anxiolytic properties. ${ }^{9}$ Intravenous opioid analgesics including short-acting agents such as alfentanil ${ }^{25}$ and remifentanil, and longer-acting agents such as morphine can provide conscious sedation prior to local anesthetic injection. Remifentanil without muscle relaxants has also been used for total intravenous anesthesia in a patient with myasthenia gravis undergoing a prolonged oculoplastic procedure. ${ }^{38}$ The intravenous agents for procedural sedation and analgesia have the potential for respiratory and/or cardiovascular compromise and should only be used by physicians trained in their safe application, who are prepared to manage the potential complications such as airway compromise. ${ }^{35}$

Ketamine is a dissociative anesthetic which makes the patients remain conscious but seem "disconnected" from their environment. ${ }^{15}$ It can be administered intravenously, intramuscularly, or orally. Since ketamine produces analgesia and sedation with relatively minimal effect on central respiratory drive, it is often used for office-based cosmetic procedures. ${ }^{69}$ However, ketamine can cause psychological disturbances on emergence with agitation, disorientation, hallucinations, and vivid dreams.

Inhalational agents such as nitrous oxide or sevoflurane can also be used for sedation in oculoplastic surgeries. This requires the presence of an anesthesiologist for their administration and monitoring and a scavenging system. In one study, sevoflurane was found to have comparable efficacy to propofol for sedation during periocular anesthetic injection, but caused post-operative nausea and vomiting and disinhibition. ${ }^{65}$

\section{Topical pre-anesthetic gels and drops}

Many delivery vehicles exist for topical anesthesia including gels, aerosol sprays, creams, ointments, drops, and patches. 
Pre-treatment with topical anesthetics may decrease the pain of local anesthetic injection required for oculoplastic procedures in children and needle phobic patients, regional local anesthetic blocks, botulinum toxin injection, and procedures such as temporal artery biopsy. Topical anesthesia has the advantages of less distortion of wound margins compared to infiltrative injections and less risk of needle-stick injury to the patient and physician.

A eutectic mixture of the local anesthetics containing $2.5 \%$ each of lidocaine and prilocaine (EMLA) is an example of a topical anesthetic emulsion, which is applied under an occlusive dressing, and requires about 60 minutes to work. EMLA cream should not be applied to the eye, but has been applied on periocular skin prior to botulinum toxin injection. ${ }^{18}$ Although EMLA is not approved for use over non-intact skin, it has been described for pre-treatment of facial lacerations. ${ }^{53}$ Prilocaine is contraindicated in methemoglobinemia.

Liposome encapsulation extends the action of a topical anesthetic. ${ }^{10}$ Topical liposomal lidocaine cream has a more rapid onset of action and is a less expensive alternative to EMLA. ${ }^{17}$ Lidocaine cream is available as an over-the-counter liposomal formulation in $4 \%$ or $5 \%$ concentrations, under the trade names of Maxilene (RGR Pharma, LaSalle, ON, Canada) and LMX (Ferndale Pharma Group, Ferndale, MI, USA). Liposomal lidocaine cream has an onset of action of about 30 minutes and unlike EMLA, an occlusive dressing is not mandatory for liposomal lidocaine. ${ }^{71}$

When local anesthetic must be injected into the posterior lamella of the lower lid, the inferior fornix can be first anesthetized with proparacaine or tetracaine-soaked cotton tip applicators. ${ }^{47}$

\section{Distraction techniques}

There are many "distraction" techniques that can be employed prior to local anesthetic injection to ease the pain and anxiety associated with injection including breathing exercises, audiovisual, and tactile techniques.

Breathing exercises have been shown to reduce the pain of injections. Children who were told to repeatedly take deep breaths during an injection were observed to express less pain than those in the control group..$^{54}$

An obstetrics study on verbal anesthesia ${ }^{68}$ found that prior to local anesthetic injection, using gentle reassuring words such as "We are going to give you a local anesthetic that will numb the area and you will be comfortable during the procedure" were preferable to the traditional pre-injection warning, "You are going to feel a big bee sting; this is the worst part of the procedure". The authors suggested that gentler terminology prior to local anesthetic injection resulted in a better subjective experience during local anesthesia compared to harsher words such as "bee sting!" "big ouch!," "lots of burning!," or “worst part!" Notwithstanding, patients receiving facial and periocular injections must be reminded not to move their head or bring up their hands during periocular injections. In patients with needle phobia, a three-step behavioral approach involving recognition and relaxation, control and preparation, and graded exposure has been described. ${ }^{70}$

Music relaxation prior to the administration of local anesthesia is well described. Many randomized control trials on the effects of music intervention in pre-operative settings found that music decreased patient's anxiety and pain. The optimal type of music was non-lyrical, with low tones, mostly strings with rare bass or percussion, and with a volume of $<60 \mathrm{~dB}$. $^{50}$

In a retrospective study investigating the effect of music during ophthalmic surgery, it was demonstrated that mean blood pressure, heart rate, and respiratory rate of patients exposed to piano music were all decreased compared to the vital signs taken in a non-music control group. Furthermore, the vitals of the patients exposed to music were lower in the operating room than in the pre-operative holding area where they were not listening to music. ${ }^{52}$

Vibration may ease pain during local anesthetic injection and botulinum toxin injection. ${ }^{60}$ The proposed mechanism of vibration anesthesia is related to the "gate control" theory of pain. ${ }^{41}$ The brain perceives less pain when the sensorial inputs to the nociceptors (pain) and mechanoreceptors (vibration) are simultaneous. One study described the use of a vibration device applied to the forehead in a circular fashion during eyelid injections, with favorable results. ${ }^{19}$

A tablet computer (eg, Apple iPad) has been described as a distraction technique to relieve anxiety during painful pediatric medical procedures. ${ }^{45}$ This may be potentially useful in oculoplastic procedures where one or both eyes can remain open for the patient to view the computer during local anesthetic injection.

Visualization techniques often with a highly geographical emphasis may help patients with needle phobia. ${ }^{4}$ Prior to anesthetic injection, the patients are asked to imagine that they are in a pleasant environment such as a tropical paradise on a sunny day.

Stress balls, holding hands with a caregiver, or hand massage ${ }^{51}$ may increase the tolerability of local anesthetic injection. When extra personnel are not available, an inflated rubber glove can be used to simulate hand holding, allowing the medical care team to continue working. 


\section{Preparation and administration of local anesthetic}

The temperature, $\mathrm{pH}$, rate of administration of the local anesthetic, and needle size may affect the patient's perception of pain during injection.

Warming the local anesthetic to body temperature can reduce the discomfort during local infiltration, compared to local anesthetic at room temperature. ${ }^{7,29}$ Applying ice to the skin or skin cooling may also decrease injection-induced pain of local anesthetics ${ }^{26}$ and periocular botulinum injections. ${ }^{18,57}$

Local anesthetic solutions are acidic and may cause a burning sensation upon injection. Buffering lidocaine to a more physiologic $\mathrm{pH}$ with sodium bicarbonate or dilute isotonic sodium chloride may decrease pain on injection. Furthermore, alkalizing the $\mathrm{pH}$ increases the portion of non-ionized lidocaine in a given solution, thus potentially enhancing penetration through the hydrophobic cell membrane. Lidocaine is marketed in an acidic solution to prolong shelf-life and should only be buffered shortly prior to administration. To buffer lidocaine, typically 1 part of $8.4 \%$ sodium bicarbonate is added to 10 parts of lidocaine $1 \%$ with 1:100,000 epinephrine. ${ }^{21}$ Studies have not consistently demonstrated a significant decrease in pain; ${ }^{16,24,44,46}$ the favorable 2010 Cochrane Systematic Review was withdrawn in 2015 due to conflicts in commercial sponsorship. ${ }^{13}$ Alkalinization of the local anesthetic did not affect the duration of anesthesia or hemostasis. Buffered lidocaine does not appear to produce more short-term complications such as post-operative bleeding, swelling, or pain than its unbuffered counterpart. ${ }^{46,49}$ Therefore, the use of buffered lidocaine is as safe as its unbuffered counterpart.

It is widely recommended that anesthetic injections should be administered slowly in the eyelid to decrease discomfort. ${ }^{27}$ The slow administration of lidocaine may have a greater impact on decreasing perceived pain than buffered lidocaine. ${ }^{58}$ The use of a microprocessor controlled delivery system to administer a constant slow rate of local anesthetic has been reported to cause less discomfort than the manual syringe technique. ${ }^{39}$ However, the speed of anesthetic delivery during retrobulbar and parabulbar injection did not significantly affect pain scores in one study. ${ }^{36}$

Smaller gauge needles may cause less pain during cutaneous insertion than larger needles, ${ }^{5}$ and local anesthetic injection with a 30 -gauge needle may be less painful than with 27 or 25 -gauge needles..$^{55}$ The authors currently use a 30 -gauge needle for local anesthetic injection in patients undergoing eyelid procedures. However, a dental study suggested that 25,27 , and 30 -guage needles caused no difference in the pain perceived ${ }^{11,20}$ and that the addition of bicarbonate to local anesthetic may have a greater overall effect than needle size in decreasing the pain associated with the intradermal injection of lidocaine. ${ }^{52}$ One small randomized control study found that botulinum toxin injection with a 32-gauge needle was less painful than a 30-gauge needle, ${ }^{2}$ but another split-face study did not support this. ${ }^{72}$

Needle-free jet injections deliver drugs percutaneously without a conventional needle and have been described for decades. ${ }^{42}$ Liquid medication is forced under high pressure through a very small orifice through the skin. However, the eye can be injured from high-pressure jet injections. Choroidal rupture with vision loss has been described after local anesthesia via jet injection. ${ }^{40}$ At the present time, needleless jet injection is not suggested for oculoplastic procedures.

\section{Precautions}

The administration of local anesthetics may have potential iatrogenic complications.

First, patients may report an allergy to local anesthetics. True allergic reactions to amide local anesthetics such as lidocaine are rare. More commonly, patients claiming allergy to amide local anesthetics are sensitive to the metabisulfite (antioxidant) or methylparaben (preservative) contained in the local anesthetic solution. ${ }^{12}$ Allergy to amide anesthetics does not cause cross-allergy to ester anesthetics. Allergies to the ester topical anesthetics are usually due to sensitivity to the metabolite para-aminobenzoic acid (PABA). If there are concerns regarding a history of allergic reaction to local anesthetics, a referral can be made for allergy testing prior to the procedure. Allergic sensitization and possible crossreaction to topical anesthetics are a potential occupational hazard for ophthalmologists, especially in providers with chronic eczema. ${ }^{14}$

Second, patients' comorbidities must be considered prior to local anesthetic injection. Local anesthetic injection may cause pupillary dilation, and periocular injections with epinephrine are a relative contraindication in patients with untreated narrow angles. Retrobulbar and parabulbar anesthetic injections should not be used for enucleation of patients with suspected intraocular tumor.

Third, periocular injections can cause injury to the globe. Several cases of globe perforation during local anesthetic injection for oculoplastic procedures have been described. ${ }^{62,67}$ To decrease this risk, a cornea protector can be placed with sterile gloves prior to injection. Appropriately tightened Luer lock syringes prevent inadvertent needle expulsion during local anesthetic administration; Luer slip syringes are not 
recommended. Bending the needle at an acute angle, keeping the needle bevel up during injection, and needle trajectories almost parallel to the tarsal plate may decrease the risk of globe injury. In anticipation of patient movement, the syringe can be nestled in a "snooker" grip, with the non-injection hand resting on the patient's forehead or cheek. Stimulation of the afferent arm of the sternutatory (sneeze) reflex by botulinum toxin injection, ${ }^{37}$ periocular local anesthetic, or with propofol may occur in $5 \%-46 \%$ of the patients, ${ }^{1,48,64}$ and the surgeon should be prepared for any associated head movements, to avert eye injury. It is speculated that propofol may suppress sneeze inhibitory neurons. Administration of an opioid prior to propofol and the local anesthetic injection may decrease the sternutatory reflex.

Finally, cross-contamination, retrobulbar hemorrhage, and intrathecal spread are potential concerns during local anesthetic injection. Labeling the syringe with the patient's identification sticker helps prevent cross-contamination if repeat injection is required. Blunt tipped retrobulbar needles (eg, Atkinson) decrease the risk of retrobulbar hemorrhage. If retrobulbar hemorrhage occurs during local anesthetic injection, procedures other than eye removal should be aborted. The patient's acuity, intraocular pressure (IOP), and swinging flashlight test should be carefully monitored. If IOP is elevated and there is a new onset of relative afferent pupillary defect, lateral canthotomy and cantholysis should be performed.

Intrathecal spread of local anesthetic is a potential complication of retrobulbar injections. The incidence of CNS depression from intrathecal anesthetic injection has been reported to be between 1 in 350 and 1 in 500 when sharp needles are used to administer anesthesia for ocular procedures. ${ }^{28}$

\section{Regional nerve blocks}

Regional nerve blocks have several advantages over local tissue infiltration. A nerve block may achieve anesthesia with a smaller volume of injection than is required for local infiltration. Unlike local tissue infiltration, nerve blocks can provide anesthesia without causing tissue distortion. This can be beneficial in situations such as severe facial lacerations or canalicular injury, in which tissue distortion may make reconstruction more difficult.

Regional anesthesia is ideal when the area of interest is innervated by a single superficial nerve. Regional blocks may be particularly advantageous in less cooperative trauma patients, so that direct infiltration does not have to be administered close to the eye.

A full discussion of the different periorbital nerve blocks is beyond the scope of this review, but the infraorbital and supraorbital nerve blocks deserve mention. Most oculoplastic surgeons are familiar with the extraoral infraorbital nerve block that can potentially anesthetize the large area between the lower eyelid and the upper lip, including the side of the nose. The infraorbital nerve foramen is $5-8 \mathrm{~mm}$ below the inferior orbital rim, in a sagittal line drawn through the medial limbus. ${ }^{73}$ The extraoral injection can be administered at a point between the upper nasolabial fold and the alar base of the nose with a 25-30-gauge needle and 2 cc of lidocaine $2 \%$ with epinephrine. As with all local anesthetic injections, the anesthetic is delivered after a negative aspiration for blood. Patients may feel an "electric shock" during the injection, and if the superior alveolar branch of the infraorbital nerve is anesthetized, the ipsilateral front teeth may feel numb.

A supraorbital nerve block with $1 \mathrm{cc}$ or less of lidocaine $2 \%$ with epinephrine has been suggested for upper eyelid surgery and may not compromise levator function, although hematomas may occasionally occur. ${ }^{34}$ The supraorbital notch is palpated near the nasal third of the superior orbital rim, and the injection is placed just lateral to the notch with a 25-30gauge needle, avoiding the supraorbital vessels. "The needle is directed posteriorly and superiorly following the curve of the orbital roof and advanced until it touches the roof" and then withdrawn slightly during anesthetic injection. ${ }^{34}$

\section{Considerations for specific procedures}

\section{Temporal artery biopsy}

Oculoplastic surgeons are frequently called upon to perform temporal artery biopsy. ${ }^{33}$ It is essential to accurately mark the location of the artery with a marking pen prior to any local anesthetic administration. In patients with a readily visible or palpable artery, epinephrine can be incorporated with the initial local anesthetic injection. In patients with limited surface vessel markings and poor arterial pulsation, epinephrine is usually not administered with the local anesthetic until after the vessel is visualized subcutaneously.

Local anesthetic is administered $\sim 1 \mathrm{~cm}$ from either side of the vessel but not into the vessel. If there is concern that the vessel markings will be obscured by the prep solution, the vessel location can be scratched with a needle tip prior to the antiseptic scrub.

\section{Eye removal and post-operative pain}

Following eye removal, patients may experience considerable post-operative discomfort. If a porous implant is used, the implant can be soaked in local anesthetic prior to placement. 
At the conclusion of the procedure, supplemental long-acting retrobulbar anesthetic is usually administered. Several temporary post-operative retrobulbar pain catheters have been described allowing patients to self-administer local anesthetic after surgery. These retrobulbar catheters have potential risk of intrathecal spread and even death. ${ }^{23}$ A parabulbar butterfly catheter technique that minimizes posterior spread of anesthetic has been described. ${ }^{30}$

\section{Cosmetic laser skin resurfacing}

Patients having cosmetic laser skin resurfacing may benefit from the specialized techniques of cryoanesthesia and tumescent local anesthesia. Cryoanesthesia can be used in conjunction with topical anesthesia and can be administered by non-contact (eg, cold sprays, forced cold air anesthesia) and contact methods (eg, sapphire cooling tip). Cryoanesthesia may not be effective in patients with cold sensitivity. ${ }^{22}$

With tumescent local anesthetic, large volumes of dilute anesthetic are administered into the subcutaneous fat, producing swelling and firmness in the surgical field. Infusion pumps are not required. A common concentration used for tumescent local anesthetic is lidocaine $0.2 \%$ with 1:100,000 epinephrine; the anesthetic can be warmed and infiltrated slowly. A "horseshoe" tumescent block typically commences at the temporal hair line and continues to the preauricular area, jaw, and chin. For the periocular area, the tumescent anesthetic can be injected from the lateral canthus to the medial canthus in the dermal plane above the orbicularis oculi. ${ }^{22}$ The tumescent anesthesia can be supplemented by regional nerve blocks.

\section{Conclusion}

Local anesthetic techniques enable patients to receive many oculoplastic surgeries in an ambulatory setting without the potential risks of general anesthesia. Local anesthetics can be administered topically, by direct infiltration or a targeted nerve block. Considerations for each technique are determined by the procedure, pathology, and comorbidities of the patient. Local anesthetic injections can cause initial patient discomfort, and maneuvers to mitigate this include pharmacologic anxiolytics, topical pre-anesthetic, distraction techniques, modifications to local anesthetic formulation and injection strategies such as warmed lidocaine, and buffered lidocaine. The anxiolytic techniques should be coordinated with adequate surgeon-patient communication including pre-operative explanations, and empathetic reassurance tailored to the individual patient.

\section{Disclosure}

The authors report no conflicts of interest in this work.

\section{References}

1. Ahn ES, Mills DM, Meyer DR, Stasior GO. Sneezing reflex associated with intravenous sedation and periocular anesthetic injection. Am J Ophthalmol. 2008;146(1):31-35.

2. Alam M, Geisler A, Sadhwani D, et al. Effect of needle size on pain perception in patients treated with botulinum toxin type a injections: a randomized clinical trial. JAMA Dermatol. 2015;151(11):1194-1199.

3. Ameer B, Greenblatt DJ. Lorazepam: a review of its clinical pharmacological properties and therapeutic uses. Drugs. 1981;21(3):162-200.

4. Andrews GJ, Shaw D. "So we started talking about a beach in Barbados": visualization practices and needle phobia. Soc Sci Med. 2010;71(10): 1804-1810.

5. Arendt-Nielsen L, Egekvist H, Bjerring P. Pain following controlled cutaneous insertion of needles with different diameters. Somatosens Mot Res. 2006;23(1-2):37-43.

6. Bartfield JM, Holmes TJ, Raccio-Robak N. A comparison of proparacaine and tetracaine eye anesthetics. Acad Emerg Med. 1994;1(4): 364-367.

7. Bell RW, Butt ZA. Warming lignocaine reduces the pain of injection during peribulbar local anaesthesia for cataract surgery. $\mathrm{Br} J$ Ophthalmol. 1995;79(11):1015-1017.

8. Lucia Bianconi M, Bianconi M. Mechanism of action of local anaesthetics: a practical approach to introducing the principles of pKa to medical students. Biochemical Education. 1998;26(1):11-13.

9. Biswas S, Bhatnagar M, Rhatigan M, Kincey J, Slater R, Leatherbarrow B. Low-dose midazolam infusion for oculoplastic surgery under local anesthesia. Eye. 1999;13(4):537-540.

10. Bucalo BD, Mirikitani EJ, Moy RL. Comparison of skin anesthetic effect of liposomal lidocaine, nonliposomal lidocaine, and EMLA using 30-minute application time. Dermatol Surg. 1998;24(5):537-541.

11. Camara JG, Ruszkowski JM, Worak SR. The effect of live classical piano music on the vital signs of patients undergoing ophthalmic surgery. Medscape J Med. 2008;10(6):149.

12. Campbell JR, Maestrello CL, Campbell RL. Allergic response to metabisulfite in lidocaine anesthetic solution. Anesth Prog. 2001;48(1): 21-26.

13. Cochrane Database of Systemic Reviews [homepage on the Internet]. Adjusting the pH of Lidocaine for Reducing Pain on Injection; 2015. Available from: https://www.cochranelibrary.com/cdsr/doi/10.1002/14651858. CD006581.pub3/information. Accessed August 14, 2018.

14. Dannaker CJ, Maibach HI, Austin E. Allergic contact dermatitis to proparacaine with subsequent cross-sensitization to tetracaine from ophthalmic preparations. Am J Contact Dermat. 2001;12(3):177-179.

15. Domino EF. Taming the ketamine tiger. Anesthesiology. 2010;113(3): 678-684.

16. Eccarius SG, Gordon ME, Parelman JJ. Bicarbonate-buffered lidocaineepinephrine-hyaluronidase for eyelid anesthesia. Ophthalmology. 1990;97(11):1499-1501.

17. Eidelman A, Weiss JM, Lau J, Carr DB. Topical anesthetics for dermal instrumentation: a systematic review of randomized, controlled trials. Ann Emerg Med. 2005;46(4):343-351.

18. Elibol O, Özkan B, Hekimhan PK, Cağlar Y. Efficacy of skin cooling and EMLA cream application for pain relief of periocular botulinum toxin injection. Ophthalmic Plast Reconstr Surg. 2007;23(2):130-133.

19. Fayers T, Morris DS, Dolman PJ. Vibration-assisted anesthesia in eyelid surgery. Ophthalmology. 2010;117(7):1453-1457.

20. Flanagan T, Wahl MJ, Schmitt MM, Wahl JA. Size doesn't matter: needle gauge and injection pain. Gen Dent. 2007;55(3):216-217.

21. Frank SG, Lalonde DH. How acidic is the lidocaine we are injecting, and how much bicarbonate should we add? Can J Plast Surg. 2012;20(2): 71-73.

22. Gaitan S, Markus R. Anesthesia methods in laser resurfacing. Semin Plast Surg. 2012;26(3):117-124. 
23. Garg S, Piva A, Sanchez RN, Sadun AA. Death associated with an indwelling orbital catheter. Ophthalmic Plast Reconstr Surg. 2003; 19(5):398-400.

24. Gershon RY, Mokriski BK, Matjasko MJ. Intradermal anesthesia and comparison of intravenous catheter gauge. Anesthesia \& Analgesia. 1991;73(4):469-470.

25. Ghosh YK, Beamer J, Ahluwalia HS. A new technique of alfentanilinduced conscious sedation for oculoplastic surgery. Orbit. 2011;30(2): $70-71$.

26. Goel S, Chang B, Bhan K, El-Hindy N, Kolli S. "Cryoanalgesic preparation" before local anaesthetic injection for lid surgery. Orbit. 2006;25(2):107-110.

27. Gupta A, Tomlins PJ, T W Ng A, Reuser TT. Alleviating pain in oculoplastic procedures by reducing the rate of injection of local anaesthetic. Open Ophthalmol J. 2015;9:156-158.

28. Hamilton RC. Brain-stem anesthesia as a complication of regional anesthesia for ophthalmic surgery. Can J Ophthalmol. 1992;27(7):323-325.

29. Hogan ME, VanderVaart S, Perampaladas K, Machado M, Einarson TR Taddio A. Systematic review and meta-analysis of the effect of warming local anesthetics on injection pain. Ann Emerg Med. 2011;58(1):86-98.e1.

30. Ing E, Al-Anezi F, Abuhaleeqa K. Postoperative analgesia with a transcutaneous parabulbar butterfly catheter. Can J Ophthalmol. 2008;43(5): 604-605.

31. Ing E, Douketis J. New oral anticoagulants and oculoplastic surgery. Can J Ophthalmol. 2014;49(2):123-127.

32. Ing E, Safarpour A, Ing T, Ing S. Ocular adnexal asymmetry in models: a magazine photograph analysis. Can J Ophthalmol. 2006;41(2):175-182.

33. Ing EB, Lahaie Luna $\mathrm{G}$, Toren A, et al. Multivariable prediction model for suspected giant cell arteritis: development and validation. Clin Ophthalmol. 2017;11:2031-2042.

34. Ismail AR, Anthony T, Mordant DJ, Maclean H. Regional nerve block of the upper eyelid in oculoplastic surgery. Eur J Ophthalmol. 2006;16(4): 509-513.

35. Jones DR, Salgo P, Meltzer J. Conscious sedation for minor procedures in adults. $N$ Engl J Med. 2011;364(25):e54.

36. Krause M, Baldus A, Spang S, Weindler J, Ruprecht KW. Comparison of analgesia and akinesia after retrobulbar injections at different speeds. Eur J Ophthalmol. 2000;10(1):66-70.

37. Kulkarni OC, Cox CA, Hedges TR 3rd, Tarsy D. Sternutatory reflex induced by periocular needle insertion in patients receiving chronic botulinum toxin injections. Parkinsonism Relat Disord. 2013;19(8):770-771

38. Lam S, Slater RM. Total intravenous anaesthesia for oculoplastic surgery in a patient with myasthenia gravis without high-dependency care. Anaesthesia. 2003;58(7):720-721.

39. Lee EW, Tucker NA. Pain associated with local anesthetic injection in eyelid procedures: comparison of microprocessor-controlled versus traditional syringe techniques. Ophthalmic Plast Reconstr Surg. 2007 23(1):37-38.

40. Lee JE, Choi HY, Lee JS, Oum BS. Posterior segment injury developed after injection of anesthetics on eyelids with needleless jet injection device. Graefes Arch Clin Exp Ophthalmol. 2007;245(1):73-175.

41. Mendell LM. Constructing and deconstructing the gate theory of pain. Pain. 2014;155(2):210-216.

42. Lysakowski C, Dumont L, Tramèr MR, Tassonyi E. A needle-free jet-injection system with lidocaine for peripheral intravenous cannula insertion: a randomized controlled trial with cost-effectiveness analysis. Anesth Analg. 2003;96(1):215-219.

43. Mancuso CE, Tanzi MG, Gabay M. Paradoxical reactions to benzodiazepines: literature review and treatment options. Pharmacotherapy. 2004;24(9):1177-1185.

44. McKay W, Morris R, Mushlin P. Sodium bicarbonate attenuates pain on skin infiltration with lidocaine, with or without epinephrine Anesthesia \& Analgesia. 1987;66(6):572-574.

45. Mcqueen A, Cress C, Tothy A. Using a tablet computer during pediatric procedures a case series and review of the "apps". Pediatr Emerg Care. 2012;28(7):712-714
46. Metzinger SE, Rigby PL, Bailey DJ, Brousse RG. Local anesthesia in blepharoplasty: a new look? South Med J. 1994;87(2):225-227.

47. Moody BR, Holds JB. Anesthesia for office-based oculoplastic surgery. Dermatol Surg. 2005;31(7 Pt 1):766-770.

48. Morley AM, Jazayeri F, Ali S, Malhotra R. Factors prompting sneezing in intravenously sedated patients receiving local anesthetic injections to the eyelids. Ophthalmology. 2010;117(5):1032-1036.

49. Narváez J, Wessels I, Bacon G, Chin VR, Baqai WK, Zimmerman GJ. Prospective randomized evaluation of short-term complications when using buffered or unbuffered lidocaine $1 \%$ with epinephrine for blepharoplasty surgery. Ophthalmic Plast Reconstr Surg. 2010;26(1):33-35.

50. Nilsson $U$. The anxiety- and pain-reducing effects of music interventions: a systematic review. Aorn J. 2008;87(4):780-807.

51. Oh HJ, Park JS. Effects of hand massage and hand holding on the anxiety in patients with local infiltration anesthesia. Taehan Kanho Hakhoe Chi. 2004;34(6):924-933. Korean

52. Palmon SC, Lloyd AT, Kirsch JR. The effect of needle gauge and lidocaine $\mathrm{pH}$ on pain during intradermal injection. Anesth Analg. 1998; 86(2):379-381.

53. Park SW, Oh TS, Choi JW, et al. Topical EMLA cream as a pretreatment for facial lacerations. Arch Plast Surg. 2015;42(1):28-33.

54. Peretz B, Gluck GM. Assessing an active distracting technique for local anesthetic injection in pediatric dental patients: repeated deep breathing and blowing out air. J Clin Pediatr Dent. 1999;24(1):5-8.

55. Ram D, Hermida BL, Amir E. Reaction of children to dental injection with 27- or 30-gauge needles. Int J Paediatr Dent. 2007;17(5):383-387.

56. Rosenberg PH, Veering BT, Urmey WF. Maximum recommended doses of local anesthetics: a multifactorial concept. Reg Anesth Pain Med. 2004;29(6):564-575; discussion 524.

57. Sarifakioglu N, Sarifakioglu E. Evaluating the effects of ice application on the pain felt during botulinum toxin type-a injections: a prospective, randomized, single-blind controlled trial. Ann Plast Surg. 2004;53(6): 543-546.

58. Scarfone RJ, Jasani M, Gracely EJ. Pain of local anesthetics: rate of administration and buffering. Ann Emerg Med. 1998;31(1):36-40.

59. Scott DB, Lee A, Fagan D, Bowler GM, Bloomfield P, Lundh R. Acute toxicity of ropivacaine compared with that of bupivacaine. Anesth Analg. 1989;69(5):563-569.

60. Sharma P, Czyz CN, Wulc AE. Investigating the efficacy of vibration anesthesia to reduce pain from cosmetic botulinum toxin injections. Aesthet Surg J. 2011;31(8):966-971.

61. Sheikh R, Dahlstrand U, Memarzadeh K, Blohmé J, Reistad N, Malmsjö M. Optimal epinephrine concentration and time delay to minimize perfusion in eyelid surgery: measured by laser-based methods and a novel form of extended-wavelength diffuse reflectance spectroscopy. Ophthalmic Plast Reconstr Surg. 2018;34(2):123-129.

62. Shiramizu KM, Kreiger AE, McCannel CA. Severe visual loss caused by ocular perforation during chalazion removal. Am J Ophthalmol. 2004;137(1):204-205.

63. Skibell B, Soparkar C, Tower R, Patrinely J. Periocular anesthesia in aesthetic surgery. Semin Plast Surg. 2007;21(1):37-40.

64. Tao J, Nunery W, Kresovsky S, Lister L, Mote T. Efficacy of fentanyl or alfentanil in suppressing reflex sneezing after propofol sedation and periocular injection. Ophthalmic Plast Reconstr Surg. 2008;24(6): 465-467.

65. Tawfik HA, Mostafa M. Sevoflurane versus propofol sedation during periocular anesthetic injections in oculoplastic procedures: An openlabel randomized comparison. Saudi J Ophthalmol. 2015;29(2): $126-129$.

66. Ullmann Y, Levy Y, Isserles S, Vohradnik G. Anesthesia for facial surgery. Aesthetic Plast Surg. 1999;23(4):296-297.

67. Vagefi MR, Lin CC, McCann JD, Anderson RL. Local anesthesia in oculoplastic surgery: precautions and pitfalls. Arch Facial Plastic Surg. 2008;10(4):246-249.

68. Varelmann D, Pancaro C, Cappiello EC, Camann WR. Nocebo-induced hyperalgesia during local anesthetic injection. Anesth Analg. 2010; 110(3):868-870. 
69. Vinnik CA. Dissociative anesthesia in an office-based plastic surgery practice. Semin Plast Surg. 2007;21(2):109-114.

70. Yim L. Belonephobia - a fear of needles. Aust Fam Physician. 2006; 35(8):623-624.

71. Yip A, Soin H, Taddio A. Review of a new topical anesthetic. CJHP. 2005;58(3):148-150.
72. Yomtoob DE, Dewan MA, Lee MS, Harrison AR. Comparison of pain scores with 30-gauge and 32-gauge needles for periocular botulinum toxin type a injections. Ophthalmic Plast Reconstr Surg. 2009;25(5): 376-377.

73. Zide BM. Surgical Anatomy Around the Orbit: The System of Zones. Philadelphia: Lippincott Williams \& Wilkins; 2006.

\section{Publish your work in this journal}

Clinical Ophthalmology is an international, peer-reviewed journal covering all subspecialties within ophthalmology. Key topics include: Optometry; Visual science; Pharmacology and drug therapy in eye diseases; Basic Sciences; Primary and Secondary eye care; Patient Safety and Quality of Care Improvements. This journal is indexed on

\section{Dovepress}

PubMed Central and CAS, and is the official journal of The Society of Clinical Ophthalmology (SCO). The manuscript management system is completely online and includes a very quick and fair peer-review system, which is all easy to use. Visit http://www.dovepress.com/ testimonials.php to read real quotes from published authors. 